\title{
Wireless Sensor Networks Based Control Strategies for the Enhancement of Reliability in Smart Grids
}

\author{
A. K. P. Kovendan, D. Sridharan \\ Department of Electronics and Communication Engineering, College of Engineering Campus Guindy, \\ Anna University, Chennai, India \\ Email: kpkvendan@gmail.com, sridhar@annauniv.edu
}

Received 24 March 2016; accepted 20 April 2016; published 25 July 2016

Copyright (C) 2016 by authors and Scientific Research Publishing Inc.

This work is licensed under the Creative Commons Attribution International License (CC BY). http://creativecommons.org/licenses/by/4.0/

c) (†) Open Access

\begin{abstract}
The rapid increase in the demand for electricity necessitates the power quality improvement for achieving better reliability in smart grids. Wireless Sensor Networks (WSN) is the proven technology for reliable monitoring. This paper proposes a system model for the development and implementation of WSN based communication system for the monitoring of distributed generation, loads and transmission lines in the electrical grid and a controller system for automated control on the electrical grid. This work also aims to reduce the carbon footprints by reducing the dependency of electrical grid through the enhancement of distributed generation and grid sharing for avoiding voltage rise problem. To achieve this, a smarter electrical grid has been developed for the validation of smart grid considering a generation substation, a transmission substation and a distributed generation with loads. The occurrence of power quality issue and voltage rise has been controlled by active power control strategy. The communication network and controller has been modeled and tested for the performance of monitoring system and data communication capability on smart grid.
\end{abstract}

\section{Keywords}

WSN, Communication System, Active Power Control, Electrical Grid, Smart Grid

\section{Introduction}

In the recent decades, GDP (Gross Domestic Product) has seen a tremendous growth. With this growth the demand for electricity has increased and forced the grid for modernization to achieve more reliability by reducing 
transmission losses and power quality issues. The electrical grid was installed in very olden times and hasn't been constructed to meet out the present days challenges that were faced now [1]. The infrastructure that acts as the backbone of a nation and being a most complex to maintain is its electrical network. The growth of a nation has been measured by the raise of its GDP, and the failure of electrical grid will in turn result in the economical losses that thwart the growth of GDP. Hence proper electrical grid is therefore needed. If the above mentioned factors like ageing have been kept apart, the concern on environment has reached to greater extinct for reducing the emission of carbon footprints and other green house gases into the atmosphere [2]. Added to that, the rise in fuel prices and rapid depletion of fossil fuels forced the interest of researchers in the field of renewable and green energy. Due to the geographical dependencies and scalability renewable energy resources got a greater impact in distributed generation. Ancient electrical grid was not designed to meet out the present day's capacity and bidirectional power flow support [3]. To address these issues smart grids emerged. When the present electrical grid becomes smarter by becoming more reliable, consistent, and affordable and encourages more distributed generation will be termed as smart grid. The traditional way of supplying energy from grid has been modified to utilize the power that has been generated in excess than the demand of that particular consumer through distributed generation by the use of renewable energy resources in some remote areas [4]. This makes the system more complex by the introduction of heterogeneity in the transmission and distribution. Hence a monitoring system and a control system were therefore needed for demand side energy management [5] [6]. If the monitoring system requires a new architecture, then the system will be less affordable due to the complexity in installation thorough out the network and economical factor is still an issue. Wireless communication will be an optimal candidate for these requirements.

Wireless Sensor Networks that play a vital role in various monitoring applications even in the most robust scenarios will be an ideal candidate [7]. Emerging of such a smarter grid will increase the reliability of the system by taking proactive measures in case of power failure and also in the occurrence of natural calamities. The increased capacity of distribution generation will facilitate the consumers through reducing their dependency on grid added to that emission of green house gases through the burning of fossil fuels will thereby reduces. These advantages were nothing when there is the occurrence of varying faults like voltage rise, reverse power flow, etc., fortunately the distributed generations uses electronic converters and inverters thus can enable islanding mode incase of grid failure or power shutdown to overcome the issues of distributed generation. Sensing and control system has three main phases namely: Sensing phase, data communication phase and control phase. The sensing part can be done effectively by the use of Wireless Sensor Nodes (WSN). WSN is a promising technology with infrastructure less nature, tiny sized and adaptability for various topologies made it possible for being an effective monitoring and enhancement of electric power systems. Data communication can be implemented with ultra low power RF signals used by WSN transceiver module. The control system can be implemented in the power electronic converters that are being used as an intermediary for the transmission of generated power into the grid.

This rest of this paper is organized as follows: the first section gives the clear state of art followed by the need for solving the identified problem by explaining the traditional methods, the third section will be the proposed methodology followed by results and discussion and the final section concludes the work and proposes the possible future research directions.

\section{Related Works}

Among the literatures available, the papers for proposing more methodologies for reliability [8]-[10], the acceptable range of T\&D losses is $6 \%$ but in some countries the ageing factor of the distribution lines lead to increase in the losses of about 40\% - 50\% [11]. Proposed a monitoring system with WSN based data acquisition for effective monitoring of power data and also indicates the theft of power is also detected in this regard [12]. States the complete state of art in utilizing the WSN based monitoring systems for smart grid applications. The reliability of WSN in terms of energy efficiency, performance has been explained in [13]-[15]. This paper proposes a novel architecture for control and monitoring system for smart grids. There are a number of works in the monitoring of smart grids [16]-[18] and WSN based monitoring applications were explained in [19] [20]. The need for integrated communication, high speed bidirectional flow of data and power for the exchange of information in mega infrastructure has been better projected in [16]. The issues related to reliability, manageability, adaptability and integrity for the deployment of heterogeneous communication system have been briefed in [21] 
[22]. The flexibility of the system for the scalability related issues and adaptability for integration of products from various vendors also plays a vital role in such types of heterogeneous networks. The use of WSN in such a complex and harsh environment has been better explained by incorporating its performance.

\section{System Model and Communication Controller}

In this section the proposed work has been briefed by explain the origin and need for the proposed work followed by the overall system architecture with the simulation parameters assumed and the scenarios considered for the same.

\subsection{Motivation}

The geographical dependencies of the renewable energy facilitated for a greater increase in the distributed generation. The generated power when exceeds the demand will result in either waste of generated power or may incur voltage snag. The demand for power has seen a tremendous level and the same can be managed by the use of distributed generation through proper balancing of system through demand management with the locally generated power.

\subsection{Proposed System}

The overall system architecture has been given in Figure 1. The system has been designed with two generation plants, a consumer and a consumer with distributed generation. The complete system has been modeled with wireless sensor networks for the acquisition of data from these units. In case of solar power plant the Power Conditioning Unit (PCU) will facilitate the islanding mode by enabling the feedback data from the grid for the synchronization. The islanding mode for consumer with distributed generation is same as the solar power unit as

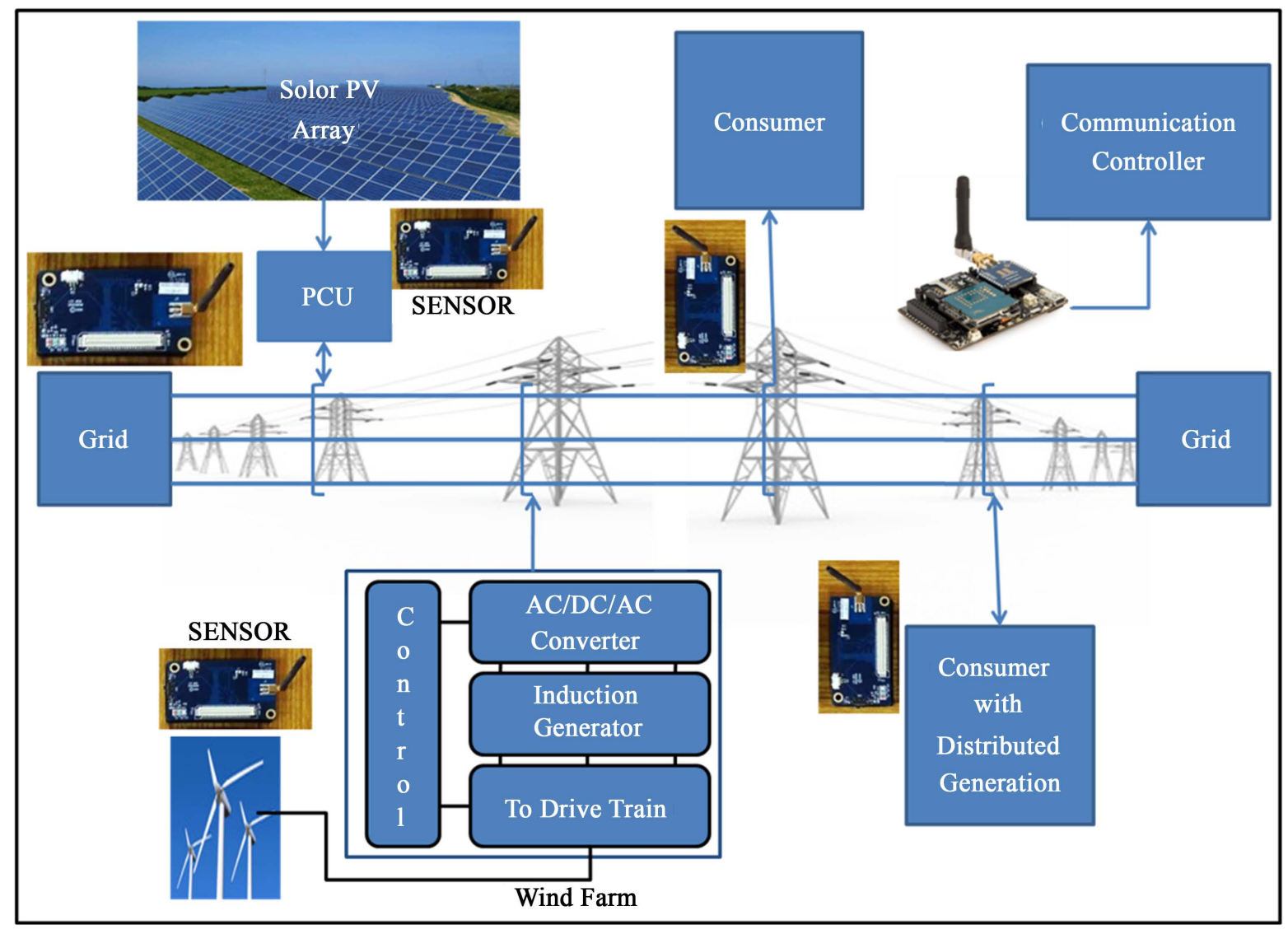

Figure 1. Monitoring and controlling system architecture for smart grids. 
the converters uses feedback data to send the excess power generated into the grid. When there is no feedback data from the sensing module it refers to the failure or shutdown of the grid. In such cases the produced power will be cutoff within the generation unit and the connection with the grid will be terminated till the reception of feedback. The islanding mode alone is not an ultimate aim but also to provide proper synchronization the generated power values like voltage and frequency. The consumer is a unidirectional user where the sensor will play a role of communication alone and the controller is therefore not needed till the occurrence of harmonics. The power quality when affected by the loads of the consumer the information will be recorded and sent to the communication controller in the interest of increasing reliable transmission by maintain the power quality. When there is exceed of rated level of harmonics to be injected then the connection will be terminated so that the power quality of the overall grid will be maintained. The wind power plant has a controller for the grid synchronization at the converter level and the data will be gathered by the communicating devices. The wireless sensor nodes with voltage and power sensors were incorporated with the transceiver module of crossbow motes mentioned as sensor in the architecture shown in Figure 1. These nodes are capable of forming a network by a group nodes connecting together without any other communication requirement like base station. The neighboring nodes will be acting as the relay and supports multi hop communication in the network.

\subsection{Performance Analysis}

The parameters that have to be monitored are voltage, power harmonics, current at the consumer side, and atmospheric data for the generation stations that were utilizing the renewable resources for the sake of the substation monitoring. The performance metrics that has to be considered for the validation are the time delay and power analysis. Data transfer rate depends on each system based on the standards followed by the system and the frequency of operation [23]. The operating frequency for WSN has been chosen at ISM band of $2.45 \mathrm{GHz}$ and the bit for the same is $4 \mu \mathrm{s}$. the total processing time for the system will depend on the data payload and data frame.

$$
T_{\text {dataPr }}=T_{\text {datapayload }}+T_{\text {pr }}
$$

$T_{\text {dataPr }}$ is the time taken for processing of the data mentioned in Equation (1) [23], which is equal to the sum of time taken data payload and the data processing time for the header and trailer bits such as preamble, frame details and also the addressing field. The power consumed for the same application can be given as follows:

$$
P_{t o t}=P_{t x}+P_{r x}+P_{p r}+P_{L}
$$

$P_{\text {tot }}$ represents the total power involved in the communication and is equal to the sum of [24] power transmitted $\left(P_{t x}\right)$, power received $\left(P_{r x}\right)$, and processing power $\left(P_{p r}\right)$ involved in the processing substation of WSN and the power lost at any three phases like sensing, transmission and processing. The transmission model has been considered as two ray ground reflection model and the path loss has been calculated accordingly. The transmitted power will be the sum of processed power and transmitted power through the antenna and is represented in Equation (3) [25] and the power within braces were the power utilized at exponential back off, channel sensing, packet transmission, buffering, power for system idle and the power for waking the device from sleep state. The received power has been mentioned in Equation (4)

$$
\begin{gathered}
P_{t x}=P_{p r}+\left(P_{\text {backoff }}+P_{c h ~ s e n s e}+P_{p k t ~ t x}+P_{\text {buff }}+P_{\text {sys idle }}+P_{\text {wakeup }}\right) \\
P_{r}=\frac{P_{t x} G_{t x} G_{r x} h_{t x}^{2} h_{r x}^{2}}{d^{4} L}
\end{gathered}
$$

\subsection{Simulation Parameters}

The system capacity designed for simulation of smart grid were solar power plant of $10 \mathrm{~kW}$, wind power plant of $10 \mathrm{~kW}$, consumer with a variable load of about $25 \mathrm{~kW}$ and the distributed generation of capacity $2 \mathrm{~kW}$ and the load for $3 \mathrm{~kW}$ has been designed. The WSN system has been tested with seven nodes for the effective communication at hardware level and 30 nodes have been created at simulation level for the validation of multi hop communication delay and the packet delivery ratio determination to ensure the performance of the system. 


\subsection{Simulation Scenario}

The system has been modeled with a certain scenarios like the grid overflow, demand exceeds the production, demand meets the production, demand is less/cutoff and the production increases rapidly and the power quality affects the grid. For these cases an algorithm has been evolved to solve such cases and the algorithm is as follows:

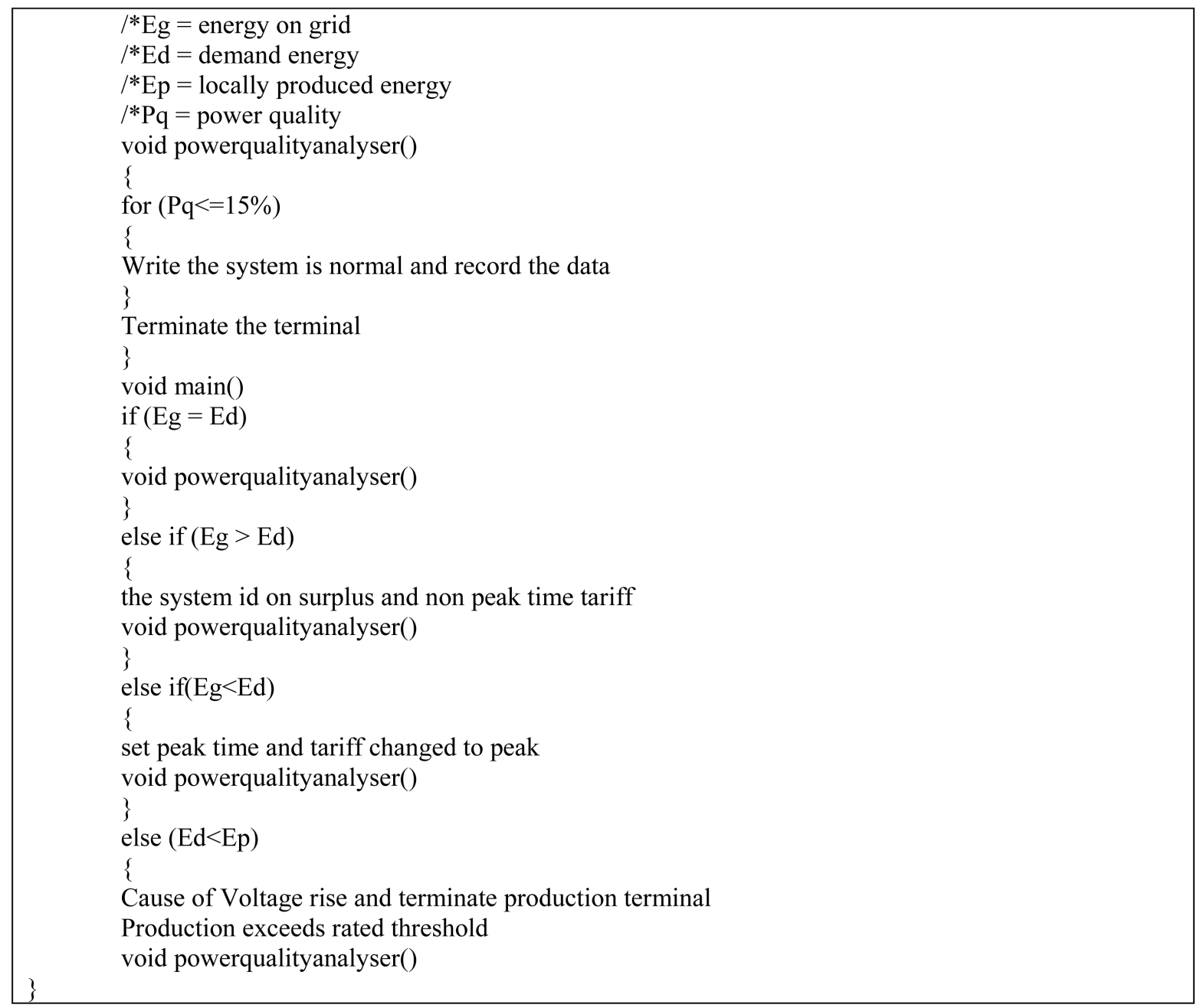

\section{Results and Discussion}

The various scenarios have been deployed in the above presented algorithm and the same has been validated through simulation analysis. The controller module performs the above mentioned functionalities like active power control strategy for maintaining the voltage rise problem. The first condition on the controller denotes the normal functionality of the grid where the demand and the grid power and generated power were maintained within the threshold and the system is at safe operating area and working fine. When this condition fails the grid power when is lower than the demand and the demand has been met by the generation capacity or maybe in deficit then the grid is said to be in the peak time the tariff has to be calculated accordingly. The vice versa case is said to non peak time and the demand will be lesser than the actual production and the grid were in safe operating with the power levels maintained within the threshold. The next case is when the demand is reduced and the production when exceeds the system will suffer from the voltage snag. This refers to the rise in voltage to a greater extinct in order to maintain the power factor along with which the frequency also increases causing instability of the grid and the loads connected to it. In that case the controller terminates the connection with the 
generation to the grid to lower the power of grid. The strategy for control the active increase in power flow is termed as active voltage control strategy and done by the controller. The next part being the communication phase, the network has been simulated by considering the two ray ground reception model and by considering the path loss the delay in packet transmission and the packet delivery ratio has been plotted in the following figures.

Figure 2 represents the number of packets contributed by each nodes in the WSN from the graph it is evident that there are 91 packets out of 30 nodes in the network. The network size has been varied from 10 to 30 and the numbers of packets were 29 to 91 respectively. The comparison given shows the proposed methodology is under performing than the existing system because of the harsh nature of deployed area and the path loss induced by the EMI/EMC effect. Figure 3 represents the packet delivery ratio for the number of nodes shown from the above Figure 2 has been plotted and the ranges were 82.2 for 70 packets from 93 for 29 packets. The energy consumption profile for the varying network size shown in Figure 4 has been plotted with the number of nodes versus consumed energy (in J). The initial energy has been assumed from $100 \mathrm{~J}$ and the average energy consumption per node will be of $6.75 \mathrm{~J}$. The remaining energy of around $80 \mathrm{~J}$ is available after the successive transmission of 30 nodes in the network. Thus the packet delivery ratio and the delay have been analyzed and a better performance has been noted in the network with minimum energy consumption of about $19.8 \mathrm{~J}$ evident in the graphs shown.

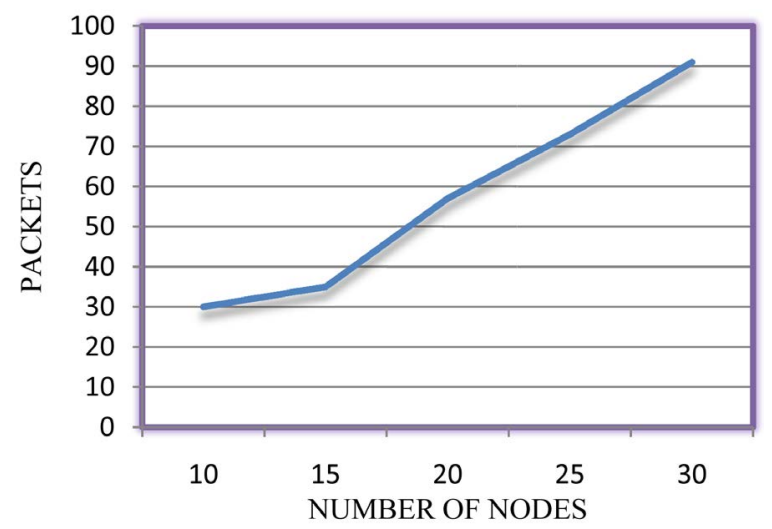

Figure 2. Number of packets versus the number of nodes.

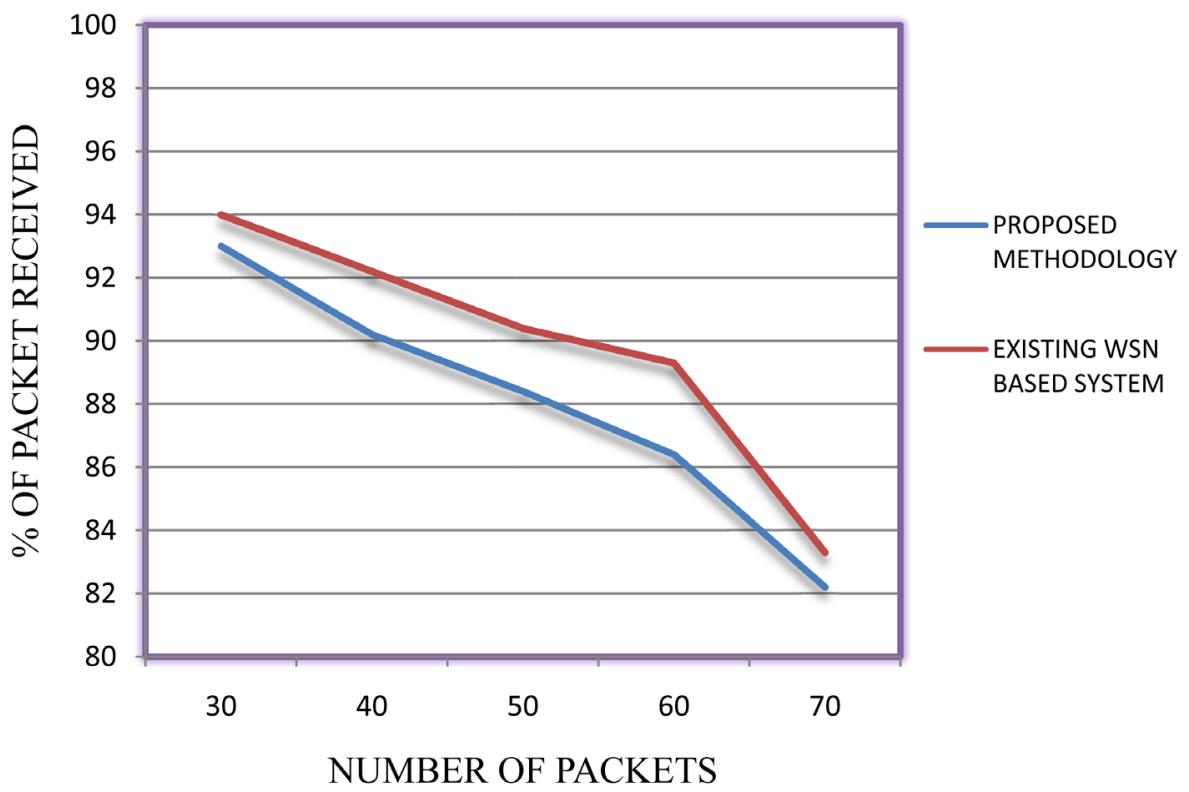

Figure 3. Packet delivery ratio versus number of packets. 


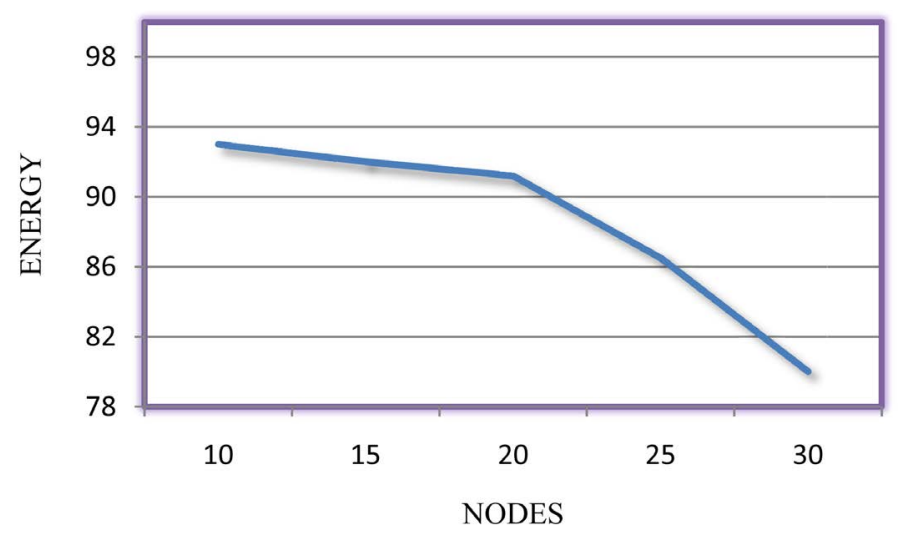

Figure 4. Energy consumption profile for varying network size.

\section{Conclusion and Future Scope}

In this paper, a communication module and a control strategy for controlling the smart grid substation for islanding of distributed generation, active power control strategy for avoiding voltage rise and voltage control strategy along with the power quality analysis has been designed implemented and validated. Through this system, better reliability has been achieved and the various scenarios for the need for control strategies like active power control, islanding power quality control have been briefed.

The future work will consider the implementation of the simulated system in a large scale by incorporating adaptive filters designed for arresting the harmonics from being injected into the grid. This can be extended for automation systems and for the monitoring of various components involved in the transmission and Distribution like transformer's oil level, etc. The cost effective and reliable monitoring system is mandatory for large scale deployment which motivates WSN design.

\section{References}

[1] McDaniel, P. and McLaughlin, S. (2009) Security and Privacy Challenges in the Smart Grid. IEEE Security \& Privacy, 3, 75-77. http://dx.doi.org/10.1109/MSP.2009.76

[2] Yang, J.I., Qian, A.I. and Da, X.I.E. (2010) Clean Energy Grid-Connected Technology Based on Smart Grid. Low Voltage Apparatus, 4, 005.

[3] Ranganathan, V. (2005) Determining T\&D Losses in India: Their Impact on Distribution Privatisation and Regulation. Economic and Political Weekly, 40, 657-668.

[4] Brown, R.E. (2008) Impact of Smart Grid on Distribution System Design. IEEE Power and Energy Society General Meeting-Conversion and Delivery of Electrical Energy in the 21st Century, Pittsburgh, 20-24 July 2008, 1-4.

[5] Logenthiran, T., Srinivasan, D. and Shun, T.Z. (2012) Demand Side Management in Smart Grid Using Heuristic Optimization. IEEE Transactions on Smart Grid, 3, 1244-1252. http://dx.doi.org/10.1109/TSG.2012.2195686

[6] Fadel, E., et al. (2015) A Survey on Wireless Sensor Networks for Smart Grid. Computer Communications, 71, 22-33. http://dx.doi.org/10.1016/j.comcom.2015.09.006

[7] Ancillotti, E., Bruno, R. and Conti, M. (2013) The Role of Communication Systems in Smart Grids: Architectures, Technical Solutions and Research Challenges. Computer Communications, 36, 1665-1697. http://dx.doi.org/10.1016/j.comcom.2013.09.004

[8] Deilami, S., Masoum, A.S., Moses, P.S. and Masoum, M.A.S. (2011) Real-Time Coordination of Plug-In Electric Vehicle Charging in Smart Grids to Minimize Power Losses and Improve Voltage Profile. IEEE Transactions on Smart Grid, 2, 456-467. http://dx.doi.org/10.1109/TSG.2011.2159816

[9] Mozina, C.J. (2013) Impact of Smart Grids and Green Power Generation on Distribution Systems. IEEE Transactions on Industry Applications, 49, 1079-1090. http://dx.doi.org/10.1109/TIA.2013.2253292

[10] Moslehi, K. and Kumar, R. (2010) Smart Grid—A Reliability Perspective. IEEE PES Conference on Innovative Smart Grid Technologies (ISGT), Washington DC, 19-20 January 2010, Paper 10 SG0068.

[11] Salvadori, F., et al. (2009) Monitoring in Industrial Systems Using Wireless Sensor Network with Dynamic Power Management. IEEE Transactions on Instrumentation and Measurement, 58, 3104-3111. http://dx.doi.org/10.1109/TIM.2009.2016882 
[12] Erol-Kantarci, M. and Mouftah, H.T. (2015) Energy-Efficient Information and Communication Infrastructures in the Smart Grid: A Survey on Interactions and Open Issues. IEEE Communications Surveys \& Tutorials, 17, 179-197. http://dx.doi.org/10.1109/COMST.2014.2341600

[13] Divya, N., Kovendan, A.K.P. and Sridharan, D. (2015) Energy Efficient Data Acquisition System for Increasing the Lifetime for WSN.

[14] Sang, Y.P., et al. (2006) Secure Data Aggregation in Wireless Sensor Networks: A Survey. IEEE 7th International Conference on Parallel and Distributed Computing, Applications and Technologies, Taipei, December 2006, 315-320. http://dx.doi.org/10.1109/pdcat.2006.96

[15] Potdar, V., Sharif, A. and Chang, E. (2009) Wireless Sensor Networks: A Survey. International Conference on Advanced Information Networking and Applications Workshops, Bradford, 26-29 May 2009, 636-641. http://dx.doi.org/10.1109/waina.2009.192

[16] Gao, J.C., Xiao, Y., Liu, J., Liang, W. and Philip Chen, C.L. (2012) A Survey of Communication/Networking in Smart Grids. Future Generation Computer Systems, 28, 391-404. http://dx.doi.org/10.1016/j.future.2011.04.014

[17] Zhang, P., Li, F.X. and Bhatt, N. (2010) Next-Generation Monitoring, Analysis, and Control for the Future Smart Control Center. IEEE Transactions on Smart Grid, 1, 186-192.

[18] Siano, P. (2014) Demand Response and Smart Grids-A Survey. Renewable and Sustainable Energy Reviews, 30, 461478. http://dx.doi.org/10.1016/j.rser.2013.10.022

[19] Yerra, R.V.P., Bharathi, A.K., Rajalakshmi, P. and Desai, U.B. (2011) WSN Based Power Monitoring in Smart Grids. 7th International Conference on Intelligent Sensors, Sensor Networks and Information Processing (ISSNIP), Adelaide, 6-9 December 2011, 401-406. http://dx.doi.org/10.1109/issnip.2011.6146589

[20] Suryadevara, N.K., Mukhopadhyay, S.C., Kelly, S.D.T. and Gill, S.P.S. (2015) WSN-Based Smart Sensors and Actuator for Power Management in Intelligent Buildings. IEEE/ASME Transactions on Mechatronics, 20, 564-571.

[21] Ullo, S., Vaccaro, A. and Velotto, G. (2010) The Role of Pervasive and Cooperative Sensor Networks in Smart Grids Communication. 15th IEEE Mediterranean Electrotechnical Conference, Valletta, 26-28 April 2010, 443-447. http://dx.doi.org/10.1109/melcon.2010.5476236

[22] Babakmehr, M., Simões, M.G., Wakin, M.B. and Harirchi, F. (2016) Compressive Sensing-Based Topology Identification for Smart Grids. IEEE Transactions on Industrial Informatics, 12, 532-543.

[23] Barclay, L.W. (2003) Propagation of Radiowaves. Vol. 502, IET. http://dx.doi.org/10.1049/PBEW502E

[24] Goldsmith, A. (2005) Wireless Communications. Cambridge University Press, Cambridge. http://dx.doi.org/10.1017/CBO9780511841224

[25] French, W.S. (1974) Two-Dimensional and Three-Dimensional Migration of Model-Experiment Reflection Profiles. Geophysics, 39, 265-277. http://dx.doi.org/10.1190/1.1440426

\section{Submit or recommend next manuscript to SCIRP and we will provide best service for you:}

Accepting pre-submission inquiries through Email, Facebook, LinkedIn, Twitter, etc.

A wide selection of journals (inclusive of 9 subjects, more than 200 journals)

Providing 24-hour high-quality service

User-friendly online submission system

Fair and swift peer-review system

Efficient typesetting and proofreading procedure

Display of the result of downloads and visits, as well as the number of cited articles

Maximum dissemination of your research work

Submit your manuscript at: http://papersubmission.scirp.org/ 